\title{
The Comparison of Plasma Cortisol Levels between 0.125\% Bupivacaine and 5 mg Continuous Oxycodone in Lower Extremity Orthopedic Surgery
}

\author{
Zulkifli $^{1}$, Agustina Haloho ${ }^{1}$, Legiran ${ }^{2}$, Pirma I.R.M ${ }^{3 *}$ \\ ${ }^{1}$ Department of Anesthesiology and Intensive Therapy, Faculty of Medicine, Universitas Sriwijaya, Palembang, Indonesia \\ ${ }^{2}$ Department of Anatomy, Faculty of Medicine, Universitas Sriwijaya, Palembang, Indonesia \\ ${ }^{3}$ Specialized Residency Training, Department of Anesthesiology and Intensive Therapy, Faculty of Medicine, Universitas \\ Sriwijaya, Palembang, Indonesia
}

*Corresponding author:

Pirma I.R.M

Specialized Residency Training, Department of Anesthesiology and Intensive Therapy, Faculty of Medicine, Universitas Sriwijaya, Palembang, Indonesia

Email:

drpm.manroe83@gmail.com

https://doi.org/10.37275/jacr.v2i2.162

\begin{abstract}
Introduction. Pain is a problem often encountered in postoperative patients. Study has shown after a procedure, $80 \%$ patients experience acute pain. This postoperative pain will affect patient's quality of life therefore necessitating quick and proper treatment. Tissue trauma during surgery will have influence on body system, including endocrine. One of endocrine system response is cortisol secretion. Cortisol levels may be attenuated by bupivacaine and oxycodone. The aim of this study was to determine the efficacy of bupivacaine $0,125 \%$ and oxycodone $5 \mathrm{mg}$ on pain perception measured by cortisol in patients undergoing orthopedic surgery of the lower limb.
\end{abstract}

Methods. A randomized clinical trial, double-blind study was performed at Mohammad Hoesin General Hospital in Palembang, South Sumatra, from November to May 2021. There were forty samples and divided into two groups (bupivacaine $0,125 \%$ and oxycodone $5 \mathrm{mg}$ ). Groups were divided by block randomization by computerized random number generator. Blinding were done by making analgesic has the same packages to prevent knowledge of which intervention is being done. Data were analyzed using independent t-test, ANOVA, Mann-Whitney and Chi Square with SPSS version 22.0.

Results: There were no statistically significant differences between the two groups on age, gender, body mass index and duration of surgery. In bupivacaine group, cortisol level decreased from $12.94 \pm 6.99 \mu \mathrm{g} / \mathrm{dl}$ to $11.32 \pm 5.42 \mu \mathrm{g} / \mathrm{dl}$ meanwhile oxycodone group cortisol levels increased from $11.81 \pm 8.47 \mu \mathrm{g} / \mathrm{dl}$ to $11.82 \pm 7.56 \mu \mathrm{g} / \mathrm{dl}$. There was no significant difference between two groups relating to cortisol levels.

Conclusions. No significant difference was found on administration of bupivacaine $0,125 \%$ and oxycodone $5 \mathrm{mg}$ as epidural analgesia on cortisol level in postoperative orthopedic surgery of the lower limb patient.

Keywords. postoperative pain, bupivacaine, cortisol, oxycodone 


\section{Journal of Anesthesiology \& \\ Clinical Research}

\section{Introduction}

Pain is a problem often experienced by postoperative patients. Studies show that after the surgical procedure, $80 \%$ of patients experience acute pain. ${ }^{1}$ This postoperative pain will have an impact on the patient's quality of life so it must be managed quickly and appropriately. ${ }^{2,3}$ A study in Kenya tried to find the prevalence of postoperative pain and found $58 \%$ of patients experienced pain within 30 minutes after surgery and persisted even after 48 hours. Another study found the prevalence of moderate and severe postoperative pain was $13 \%$ after 24 hours and $11.7 \%$ after 48 hours. ${ }^{3}$ At Dr.Mohammad Hoesin General Hospital, Anugerah in 2014 said that from a total of 35 samples, patients who experienced heavy pain was found as many as 20 people $(57.1 \%) .{ }^{4}$ it means, postoperative pain management is still bad.

Tissue trauma that occurs during surgery not only has an impact on peripheral sensitization but also has an impact on body systems, one of which is the endocrine system. Pain obtained due to tissue trauma during surgery can activate the hypothalamic-pituitary-adrenal (HPA) axis and trigger the release of releasing factors. ${ }^{6-8}$ Releasing factors then trigger the anterior pituitary to secrete adrenocorticotropic hormone (ACTH) and lead to the release of cortisol. The increase of cortisol levels due to surgery varies depending on the degree of surgery the patient.

In addition, the occurrence of stress, both physical and neurogenic causes the activation of the HPA axis (hypothalamic-pituitary-adrenal axis). Corticotropin releasing hormone (CRH) will be secreted by the hypothalamus and trigger the release of adrenocorticotropic hormone (ACTH) by the pituitary and eventually trigger the release of cortisol in the adrenals. Surgery causes stress and trauma so cortisol secretion can increase significantly postoperatively. ${ }^{6-11}$

Not only stress and trauma factors but also anesthetic technique can affect the response of cortisol. This statement is supported by the finding that cortisol levels increased minimally in patients given epidural anesthesia only minimally increased compared to those given general anesthesia. This situation can be explained by the fact that epidural anesthesia can block afferent nerve impulses from surgical trauma and consequently lower cortisol. ${ }^{12}$

One of the most commonly performed operations is orthopedic surgery. Based on data from patients who have elective orthopedic surgery at the Central Surgical Installation of Dr.Mohammad Hoesin General Hospital Palembang in 2011-2015, the total number of patients was 511-1013 people each year with an average of 52-85 patients each month. Of all these orthopedic surgeries, approximately 55-60\% are lower extremity surgical procedures. ${ }^{4}$ Bupivacaine is a long-acting local anesthetic and has a potency about four 


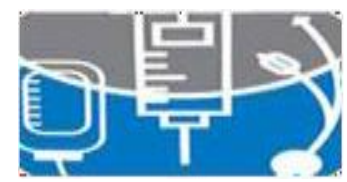

\section{Journal of Anesthesiofogy \& \\ ClinicalResearch}

times that of lidocaine and produces more sensory than motor block. Oxycodone is a class of opioids that is increasingly being used as postoperative analgesia because of its minimal side effects compared to other opioids such as morphine. The aim of this study was to determine the efficacy of bupivacaine $0,125 \%$ and oxycodone $5 \mathrm{mg}$ on pain perception measured by cortisol in patients undergoing orthopedic surgery of the lower limb.

\section{Methods}

This study was a double-blind randomized controlled trial. The data were primary data from patients who were given either $0.125 \%$ bupivacaine or $5 \mathrm{mg}$ continuous perepidural oxycodone. Bupivacaine $0.125 \%$ is the drug that is the standard of therapy, while oxycodone $5 \mathrm{mg}$ is the comparison drug. This research was done at the Central Surgical Installation (IBS) Dr.Mohammad Hoesin Hospital Palembang from November until finished. The population and sample of the study were all patients who have lower extremity orthopedic surgery at Dr.Mohammad Hoesin Hospital Palembang and were given anesthesia through an epidural catheter.

Inclusion criteria in this study were patients who will get lower extremity surgery, ASA I-II physical status, patients aged 17-64 years, willing to be research participants and signing informed consent. Exclusion criteria in this study were patients with contraindications to administration of bupivacaine and oxycodone and patients who contraindicated administration of epidural anesthesia. The dropout criteria in this study were complications during surgery, patients requiring general anesthesia, epidural failure, and patients requiring additional analgesia. Withdrawal criteria in this study were patients who were previously willing to take part in the study and then bow out.

The sample size in this study was calculated using the sample calculation formula, so that the minimum number of samples at each group was 36 subjects. To anticipate sample shortages, the number of samples was added by a $10 \%$ dropout to 40 subjects. The research groups were treatment group I (bupivacaine $0.125 \%$ ) and treatment group II (oxycodone $5 \mathrm{mg}$ ). The group was devided by block randomization. The method used computerized random number generator. The researcher determined that each block consisted of 2 subjects and each block consisted of group I, first continuous $0.125 \%$ bupivacaine and group II, then continuous $5 \mathrm{mg}$ oxycodone, so there are two possibilities, blocks I-II or blocks II-I. Blocks are then assigned an odd number code for blocks I-II and even numbers for blocks II-I. The numbers are then randomized and then replaced with the corresponding blocks.

The procedure in this study uses the blinding technique. Oxycodone and bupivacaine have been 


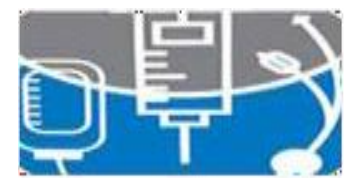

\section{Journal of Anesthesiology \& \\ ClinicalResearch}

prepared in exactly the same $125 \mathrm{cc}$ easy pump packaging to prevent officers from knowing what intervention will be given to research subjects. The independent variables in this study were $0.125 \%$ Bupivacaine, and $5 \mathrm{mg}$ oxycodone. The dependent variable in this study was changes in plasma cortisol levels, side effects and pain scale. The confounding variables in this study were age, body mass index, gender, duration of surgery. After get approval from the Health Research Ethics Committee, samples that match the inclusion and exclusion criteria were asked for informed consent 1 day before sampling. Then the sample was divided into two groups with the intervention of bupivacaine and oxycodone. After surgery, plasma cortisol levels were checked. The success parameter of this study was that there was a significant difference in cortisol levels in $5 \mathrm{mg}$ oxycodone compared to $0.125 \%$ bupivacaine which was given as postoperative epidural analgesia for the lower extremities. The data that has been collected is inputted and analyzed by univariate and multivariate analysis using SPSS version 23.

\section{Results}

\section{Sociodemographic and clinical characteristics between test groups}

Table 1 presents the sociodemographic and clinical characteristics between the test groups. In the $0.125 \%$ bupivacaine group, the study subjects had a mean age of 43.05 years with a standard deviation of 14.66. Research subjects have the same proportion for male and female, it was $50 \%$. Most of the respondents had a normal BMI, which was 10 people (50\%). 5 people (25\%) had less BMI and 5 people (25\%). The duration of surgery in the $0.125 \%$ bupivacaine group had an avarege of 156.65 minutes.

The study subjects in the $5 \mathrm{mg}$ oxycodone group had an average age of 39.85 with a standard deviation of 14.83. Most of the research subjects were male with a total of 14 people (70\%). Most of the respondents had a normal BMI, which was 10 people (50\%). 3 people (15\%) had less BMI, 7 people (35\%) had overweight BMI and $2(10 \%)$. The duration of surgery in the $5 \mathrm{mg}$ oxycodone group had a mean of 132.35 minutes. The results of the analysis using the Mann-Whitney and Chi-Square tests showed that there was no significant difference between the general characteristics between the two test groups ( $p>0.05)$ so that it was worth comparing. 


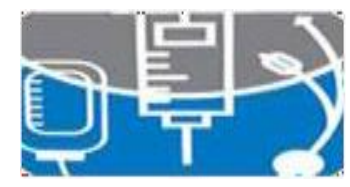

\section{Journal of Anesthesiology \& \\ Clinical Research}

Table 1 Sociodemographic and clinical characteristics between test groups

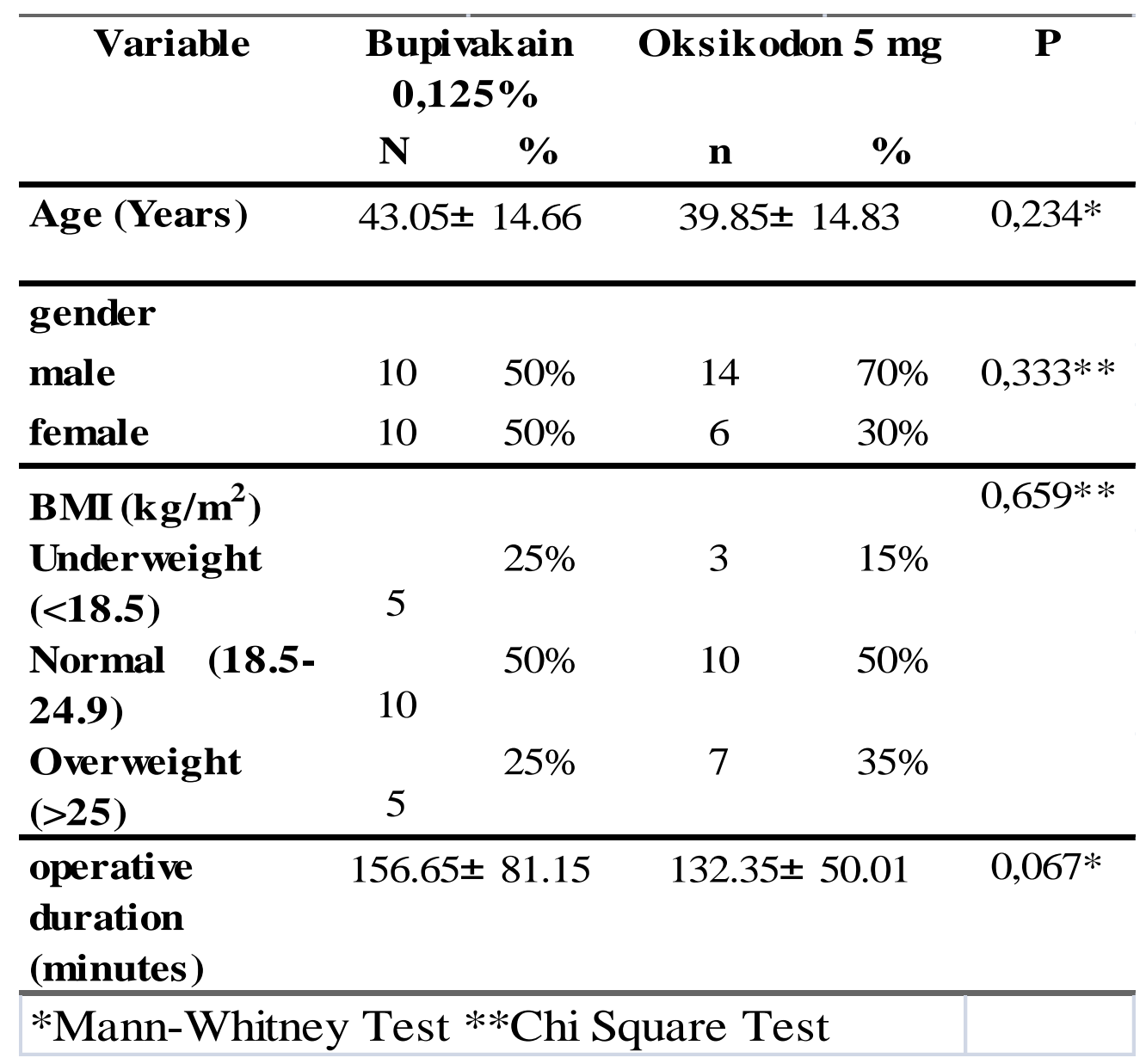

Initial cortisol levels (T0) based on sociodemographic and clinical characteristics between test groups

Table 2 presents baseline cortisol levels (T0) based on sociodemographic and clinical characteristics between the test groups. In the $0.125 \%$ bupivacaine test group, according to age group, the category with

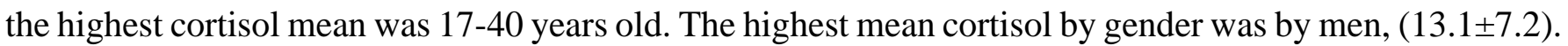
The highest mean cortisol according to BMI is underweight category and the smallest by the normal category. The duration of surgery with the highest mean cortisol was in the 100 minute group.

In the $5 \mathrm{mg}$ oxycodone test group, according to age group, the category with the highest average cortisol group was in the 41-64 year. The highest mean cortisol by gender was male (13.3 \pm 8.7$)$. The highest cortisol mean according to BMI was normal category and the smallest by the overweight category. The duration of surgery with the highest mean cortisol belonged to the 100 minute group.

Table 2 also shows the final cortisol level (T1) based on sociodemographic and clinical characteristics between the test groups. In the $0.125 \%$ bupivacaine test group, according to age group, the category with 


\section{Journal of Anesthesiology \& \\ ClinicallResearch}

the highest cortisol mean was 17-40 years old with a cortisol level of $13.4+5.7$. The highest mean cortisol by gender was male $(12.1 \pm 5.8)$. The highest mean cortisol according to BMI was underweight category with a value of $15.1+5.6$ and the smallest by the overweight category with a cortisol level of $10.0+6.8$. The duration of surgery with the largest cortisol mean was owned by the $<100$ minutes (Short) group with a value of $12.7+4.4$

Table 2. Cortisol levels based on sociodemographic and clinical characteristics between test groups

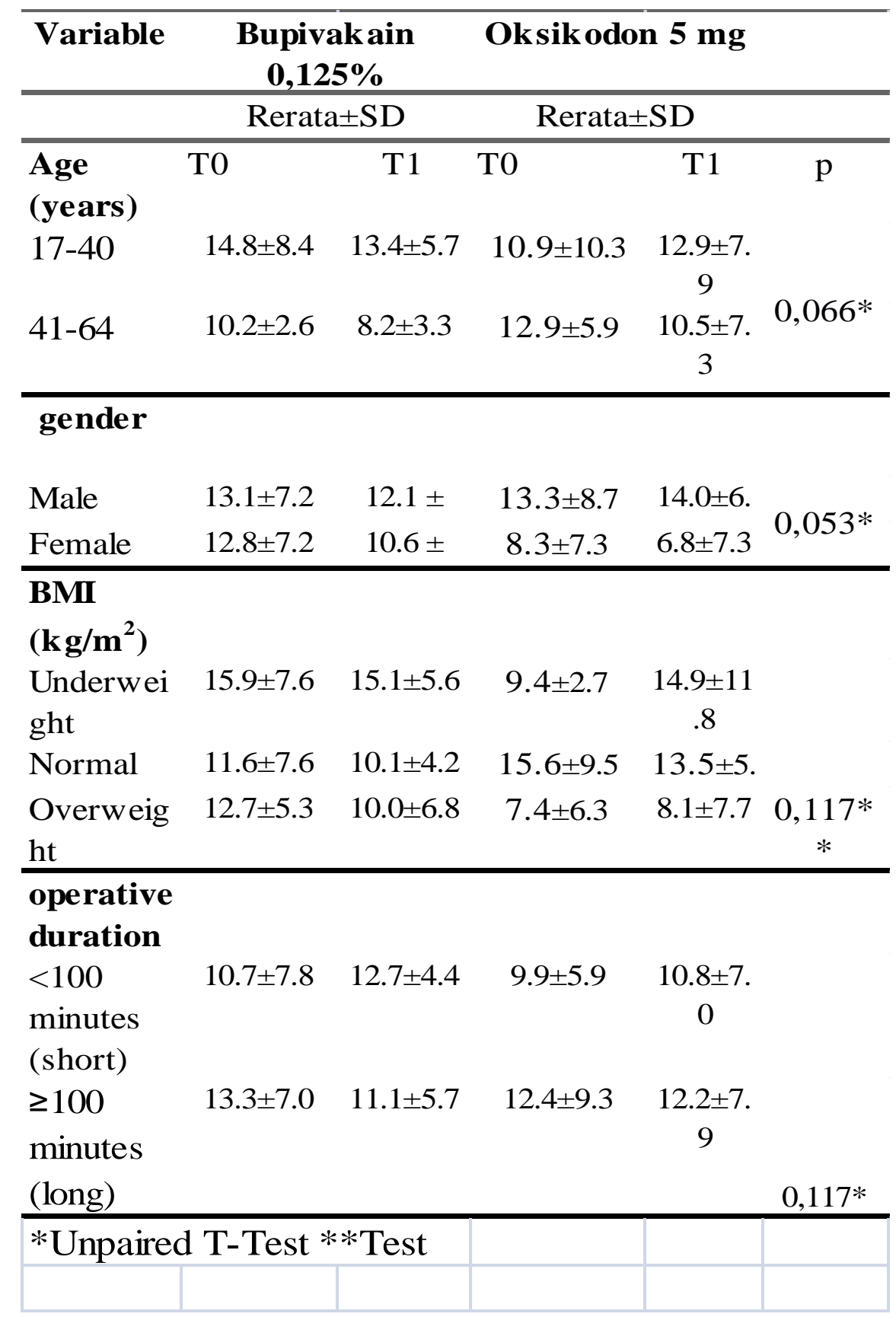


In the $5 \mathrm{mg}$ oxycodone test group, according to age group, the category with the highest mean cortisol group was 17-40 years old with cortisol levels of $12.9+7.9$. The highest mean cortisol by gender was by male (14.0 \pm 6.8$)$. The highest mean cortisol according to BMI was by underweight category $(14.9+11.8)$. The duration of surgery with the highest mean cortisol was by the 100 minute group (long) $12.2+7.9$. The results analysis by using unpaired T-test and ANOVA showed that there was no difference in average cortisol between the two test groups ( $p>0.05)$ according to each respondent's characteristics.

\section{The changes in plasma cortisol levels between test groups}

Based on table 3 , from $0.125 \%$ bupivacaine test group, according to age group, the category with the highest average change in cortisol was in the 41-64 year age range, with a value of $-2.04 \pm 4.11$. The highest change in mean cortisol by gender was by female $(2.23 \pm 5.76)$. The highest average change in cortisol according to BMI was overweight category, with a value of $-2.74 \pm 4.29$. The duration of surgery with the highest change in mean cortisol was by the group $>100$ minutes (length) with a value of $-2.25 \pm 4.69$.

In the $5 \mathrm{mg}$ oxycodone test group, according to age group, the category with the highest average change in cortisol was in 41-64 year age range with a value of $-2.47 \pm 7.52$. The highest change in average cortisol by gender was male $(2.71 \pm 12.47)$. The highest change in average cortisol according to BMI was underweight category with a value of $5.50 \pm 13.39$. The duration of surgery with the highest mean change in cortisol was $<100$ minutes (Short) group with a value of $0.84 \pm 11.40$. The results analysis by using unpaired T-test and ANOVA showed that there was no difference in mean cortisol between the two test groups ( $p>0.05)$ according to each respondent's characteristics.

Table 3. The changes in plasma cortisol levels between test groups

\begin{tabular}{lccc}
\hline Variable & $\begin{array}{c}\text { Bupivakain } \\
\mathbf{0 , 1 2 5 \%}\end{array}$ & Oksikodon 5 mg & P \\
\hline Age & Rerata \pm SD & Rerata \pm SD & \\
(years) & & & \\
$17-40$ & $-1.34 \pm 5.38$ & $2.04 \pm 11.62$ & $0.315^{*}$ \\
$41-64$ & $-2.04 \pm 4.11$ & $-2.47 \pm 7.52$ & \\
\hline Gender & & & \\
male & $-1.01 \pm 3.83$ & $2.71 \pm 12.47$ & $0,458^{*}$ \\
female & $-2.23 \pm 5.76$ & $-1.47 \pm 6.88$ & \\
\hline
\end{tabular}




\begin{tabular}{lccc}
\hline \multicolumn{1}{c}{ Variable } & $\begin{array}{c}\text { Bupivakain } \\
\mathbf{0 , 1 2 5 \%}\end{array}$ & $\begin{array}{c}\text { Oksikodon } \\
\mathbf{5} \mathbf{~ m g}\end{array}$ & P \\
\hline & Rerata \pm SD & Rerata \pm SD & \\
\hline BMI $\left(\mathbf{k g} / \mathbf{m}^{2}\right)$ & & & \\
Underweight & $-0.82 \pm 3.37$ & $5.50 \pm 13.39$ & \\
Normal & $-1.46 \pm 5.86$ & $-2.11 \pm 7.76$ & $0,968^{* *}$ \\
Overweight & $-2.74 \pm 4.29$ & $0.69 \pm 12.0$ & \\
\hline $\begin{array}{l}\text { operative } \\
\text { duration }\end{array}$ & & & \\
$<100$ minutes & $1.97 \pm 4.50$ & $0.84 \pm 11.40$ & \\
(short) & & & $0,604 *$ \\
$\geq 100$ minutes & $-2.25 \pm 4.69$ & $-0.27 \pm 9.93$ & \\
(long) & & & \\
\hline *Unpaired T-Test $* *$ ANOVA Test & \\
\hline
\end{tabular}

Differences in plasma cortisol levels between test groups differences in plasma cortisol levels between test groups

Table 4 presents data of differences plasma cortisol levels between test groups. There was no significant difference between the mean cortisol (T0) of $0.125 \%$ bupivacaine and $5 \mathrm{mg}$ oxycodone $(\mathrm{p}=0.650)$. The highest mean cortisol was at $0.125 \%$ bupivacaine group. Furthermore, there was no significant difference between the mean final cortisol (T1) between the $0.125 \%$ bupivacaine group and the $5 \mathrm{mg}$ oxycodone group having the highest mean cortisol $(\mathrm{p}=0.810)$. Comparison of changes in the mean cortisol levels of $0.125 \%$ bupivacaine with $5 \mathrm{mg}$ oxycodone changed significantly $(\mathrm{p}=0.515$ ).

Table 4. Differences in plasma cortisol levels between test groups

\begin{tabular}{lccl}
\hline Variable & $\begin{array}{c}\text { Bupi vakain } \\
\mathbf{0 , 1 2 5 \%}\end{array}$ & $\begin{array}{c}\text { Oksikodon 5 } \\
\text { mg }\end{array}$ & P value \\
\hline & Rerata \pm SD & Rerata \pm SD & \\
\hline T0 & $12.94 \pm 6.99$ & $11.81 \pm 8.47$ & $0.650^{*}$ \\
\hline T1 & $11.32 \pm 5.42$ & $11.82 \pm 7.56$ & $0.810^{*}$ \\
\hline$\Delta \mathbf{T}$ & $-1.6 \pm 4.80$ & $0.01 \pm 10.01$ & $0.515^{*}$ \\
\hline *Unpaired T-Test & & \\
\hline
\end{tabular}




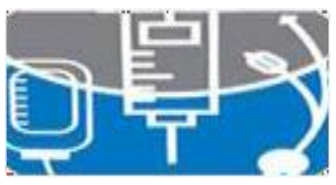

\section{Journal of Anesthesiology \& \\ Clinical Research}

\section{The Differences in side effects between test groups}

Table 5 showed side effect data between test groups. In the $0.125 \%$ bupivacaine group, it was found that the majority of side effects were nausea and vomiting, as many as 2 people. Meanwhile, in the $5 \mathrm{mg}$ oxycodone group, the side effects was chills, as many as 3 people. Differences in side effects between groups of $0.125 \%$ bupivacaine and $5 \mathrm{mg}$ oxycodone were tested using Fisher's Exact analysis. For the side effect of shivering, there was no significant difference between the administration of $0.125 \%$ bupibacaine and $5 \mathrm{mg}$ oxycodone $(\mathrm{p}=0.302)$. For the side effect of nausea, the administration of $0.125 \%$ bupivacaine and $5 \mathrm{mg}$ oxycodone did not have a significant difference between the two test groups $(\mathrm{p}=0.698)$. For the vomiting category, there was no significant difference between the two test groups $(\mathrm{p}=0,500)$.

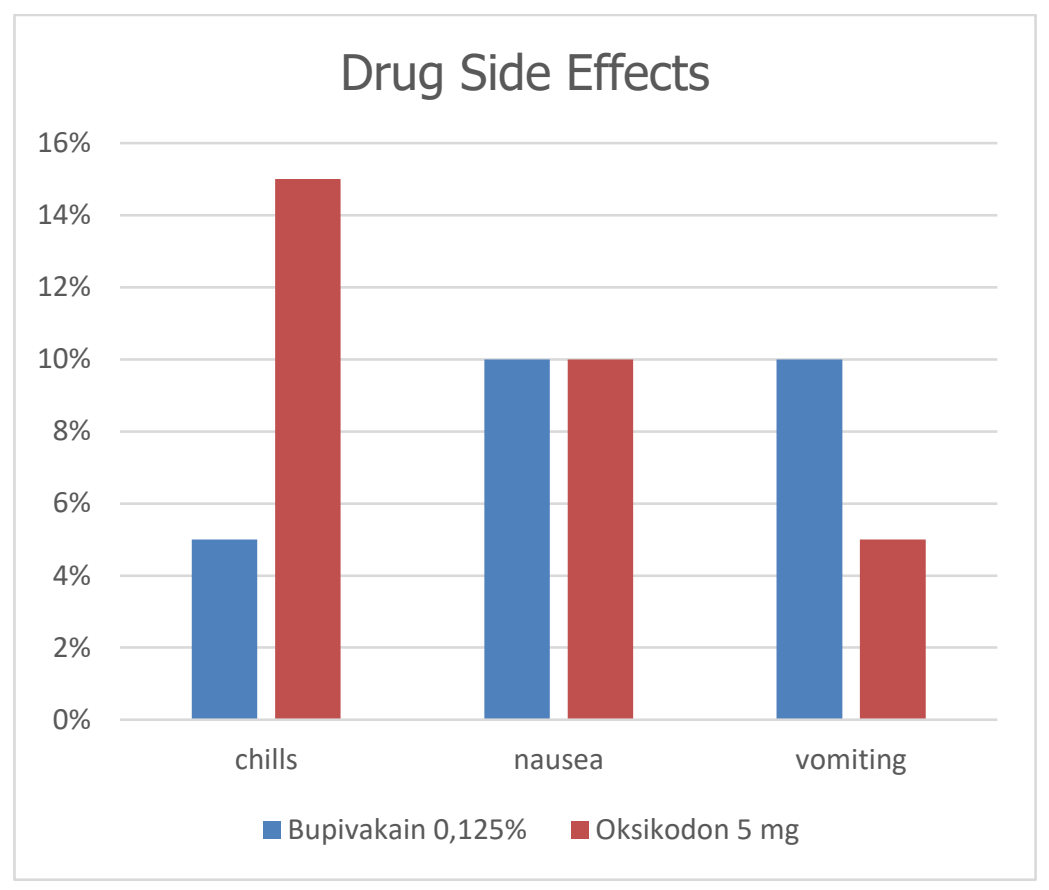

Figure 1. Bar graph of side effects between test groups. There was no incidence of hypotension, bradycardia and respiratory depression in the patient. 


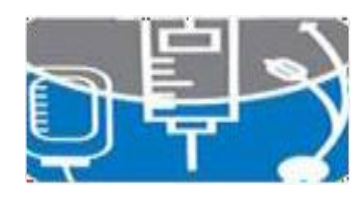

\section{Journal of Anesthestology \& \\ Clinical Research}

Table.5. Differences in side effects between test groups

\begin{tabular}{|c|c|c|c|c|c|}
\hline \multirow[t]{2}{*}{ Side effects } & \multicolumn{2}{|c|}{$\begin{array}{c}\text { Bupivakain } \\
0,125 \%\end{array}$} & \multicolumn{2}{|c|}{$\begin{array}{c}\text { Oksikodon } 5 \\
\text { mg }\end{array}$} & \multirow[t]{2}{*}{$\begin{array}{c}\mathbf{p} \\
\text { value }\end{array}$} \\
\hline & $\mathrm{n}$ & $\%$ & $\mathrm{~N}$ & $\%$ & \\
\hline \multicolumn{6}{|l|}{ Hypotension } \\
\hline Yes & 0 & $0 \%$ & 0 & $0 \%$ & \\
\hline NO & 20 & $100 \%$ & 20 & $100 \%$ & \\
\hline \multicolumn{6}{|l|}{ tachycardia } \\
\hline Yes & 0 & $0 \%$ & 0 & $0 \%$ & \\
\hline No & 20 & $100 \%$ & 20 & $100 \%$ & \\
\hline \multicolumn{6}{|l|}{ bradycardia } \\
\hline yes & 0 & $0 \%$ & 0 & $0 \%$ & \\
\hline NO & 20 & $100 \%$ & 20 & $100 \%$ & \\
\hline \multicolumn{6}{|l|}{ Chills } \\
\hline Yes & 1 & $5 \%$ & 3 & $15 \%$ & \multirow{2}{*}{$0,302 *$} \\
\hline NO & 19 & $95 \%$ & 17 & $85 \%$ & \\
\hline \multicolumn{6}{|l|}{ Nausea } \\
\hline Yes & 2 & $10 \%$ & 2 & $10 \%$ & \\
\hline No & 18 & $90 \%$ & 18 & $90 \%$ & $0,698^{*}$ \\
\hline \multicolumn{6}{|l|}{ Vomiting } \\
\hline Yes & 2 & $10 \%$ & 1 & $5 \%$ & \\
\hline No & 18 & $90 \%$ & 19 & $95 \%$ & $0,500 *$ \\
\hline \multicolumn{6}{|l|}{$\begin{array}{l}\text { respiratory } \\
\text { distress }\end{array}$} \\
\hline Yes & 0 & $0 \%$ & 0 & $0 \%$ & \\
\hline no & 20 & $100 \%$ & 20 & $100 \%$ & \\
\hline
\end{tabular}

*Fisher exact test

\section{Differences in BSS Levels between Test Groups}

Table 6 showed the differences in BSS levels between test groups and Figure 4.3 Showed line graph differences in BSS levels. It can be seen that the mean baseline BSS level in the $5 \mathrm{mg}$ oxycodone group was higher than the bupivacaine group $(131 \pm 32 \mathrm{mg} / \mathrm{dl})$ compared to $118 \pm 16 \mathrm{mg} / \mathrm{dl}$. However, in the MannWhitney test, there was no significant difference in baseline BSS levels between the test groups so that the two variables were feasible to be compared $(\mathrm{p}=0.065, \mathrm{p}>0.05)$. The difference in level changes for $0.125 \%$ bupivacaine was $10 \mathrm{mg} / \mathrm{dl}$ while $5 \mathrm{mg}$ oxycodone was $19 \mathrm{mg} / \mathrm{dl}$ so that $0.125 \%$ bupivacaine was better in reducing cortisol levels than $5 \mathrm{mg}$ oxycodone descriptively. However, in the Mann-Whitney test, there was no difference in the mean BSS levels between the two groups $(\mathrm{p}=0.579, \mathrm{p}>0.05)$. 


\section{Journal of Anesthesiology \& \\ Clinical Research}

Table 6. Differences in BSS levels between test groups

\begin{tabular}{lccc}
\hline Variable & $\begin{array}{c}\text { Bupivakain } \\
\mathbf{0 , 1 2 5 \%}\end{array}$ & $\begin{array}{c}\text { Oksikodon 5 } \\
\text { mg }\end{array}$ & p value \\
\hline Rerata \pm SD & Rerata \pm SD & \\
\hline BSS (before) & $118 \pm 16$ & $131 \pm 32$ & $0.065^{*}$ \\
\hline BSS (After) & $128 \pm 27$ & $150 \pm 80$ & $0.579^{*}$ \\
\hline *Mann- Whitney test & & \\
\hline
\end{tabular}

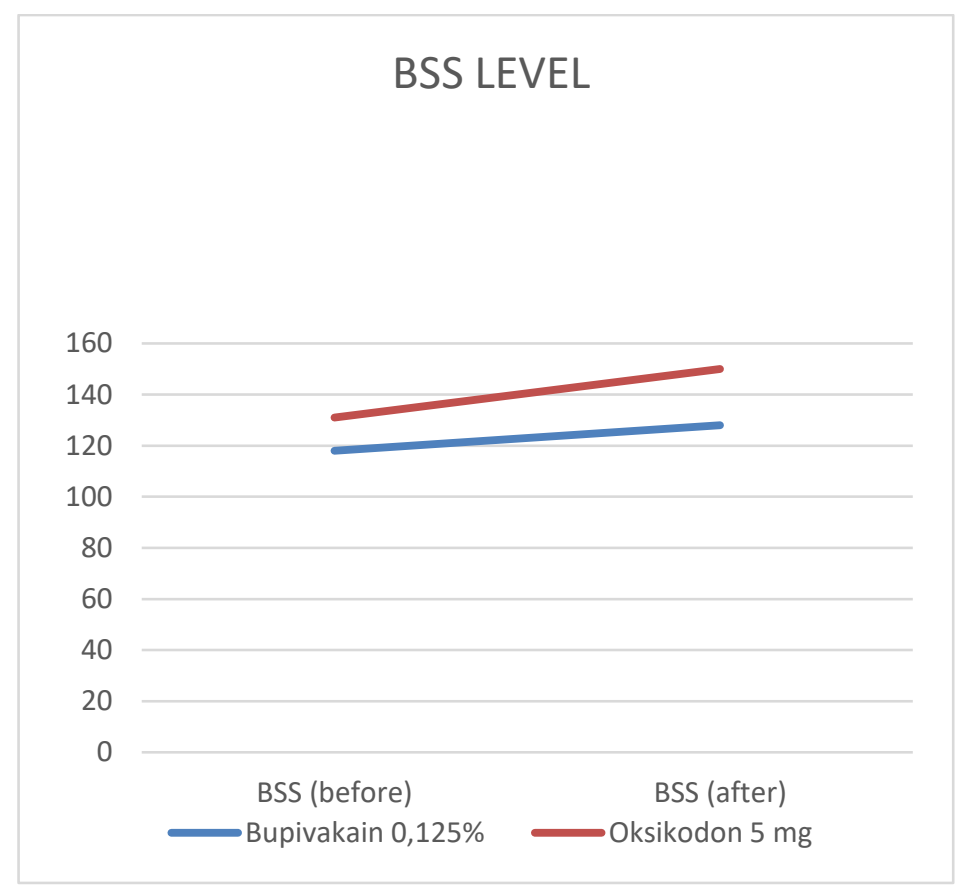

Figure 2. Line graph of differences in BSS levels between test groups

\section{Discussion}

\section{Sociodemographic and clinical characteristics between test groups}

The characteristics of the $0.125 \%$ bupivacaine test group have a mean age of $43.05 \pm 14.66$. In the administration of $5 \mathrm{mg}$ oxycodone, the mean age was $39.85 \pm 14.83$ which indicated that the characteristics between the two test groups were not statistically significant $(\mathrm{p}=0.234)$. Meanwhile, the age characteristics of the results of the study conducted by Sahin et al were found that the mean age in the bupivacaine group was 47.0 \pm 12.0 years and in the levobupivacaine group was $44.0 \pm 11.0$ years. ${ }^{55}$ In line with this, Lierz et al also had a similar age distribution of $49.0 \pm 20.1$ for the bupivacaine group and $50.3 \pm 19.5$ years for the 


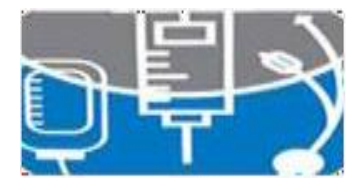

\section{Journal of Anesthesiology \& \\ Clinical Research}

ropivacaine group. ${ }^{56}$ However, this study is similar to that reported by Yovalina et al in that the mean age was $38.2 \pm 16.31$ for the bupivacaine group. ${ }^{57}$ For epidural administration of oxycodone when compared with the study of Ban Leong et al. for age characteristics, the mean age in the group given epidural oxycodone was 32.1 years. ${ }^{58}$

The research subjects for the sex variable in the $0.125 \%$ bupivacaine test group had the same proportions for male and female, it was $50 \%$. In the gender variable for the bupivacaine group, this study had a similar distribution with Sahin et al, 53.3\% for male and $46.7 \%$ for femal in the bupivacaine group meanwhile for the levobupivacaine group data obtained were $63.3 \%$ male and $36,67 \%$ female. ${ }^{55}$ Table 4.1 , showed 25\% less BMI, 50\% normal BMI, and 25\% overweight for the category of bupivacaine. Yovalina et al's study also found similar results for the distribution of sex and BMI in the bupivacaine group, it was $40.7 \%$ for male and $62.2 \%$ for female and the majority of patients had normal BMI. On the other hand, the study of Yovalina and friends, the duration of surgery in this study was longer, with a mean of $156.65 \pm 81.15$ minutes compared to 127 minutes in the study of Yovalina et al.. ${ }^{57}$

The average BMI for the administration of $5 \mathrm{mg}$ oxycodone per epidural, the majority of which were normal (50\%). Meanwhile, according to a study by BanLeong et al reported a different distribution of respondents in the BMI category of oxycodone, the majority of respondents in the study were overweight. ${ }^{58}$ Supporting the results of this study, Bialka et al also had a BMI distribution in which the majority were normal BMI. ${ }^{59}$ The duration of surgery in the oxycodone group had mean $132.35 \pm 50.01$, different from the previous study which had a mean of 212 minutes. ${ }^{14}$

In this study, there were no significant differences in general characteristics between the two groups. It is important especially for the age and duration of surgery. Although the operations were performed by different surgeons, the mean duration was not significantly different. The duration of surgery is important because it can affect the release of neuroendocrine hormones such as cortisol due to tissue injury during surgical incision and lengthened tissue manipulation time. ${ }^{54}$ The relationship between age and sex on cortisol levels is still unknown certaintly and may involve a decrease in HPA axis resistance making cortisol reduction more difficult. to happen. ${ }^{60}$

\section{Differences in plasma cortisol levels between test groups}

In Table 4 showed cortisol levels for the $0.125 \%$ bupivacaine test group had a $\mathrm{T}$ value $=-1.6+4.80$ and in the $5 \mathrm{mg}$ oxycodone test group a $\mathrm{T}$ value $=0.01+10.01$. This proves that the $0.125 \%$ bupivacaine group found a lower $\mathrm{T} 1$ value than $\mathrm{T} 0$ while the $5 \mathrm{mg}$ oxycodone group found a higher $\mathrm{T} 1$ value than $\mathrm{T} 0$. 


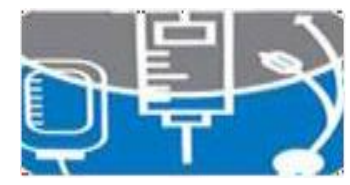

\section{Journal of Anesthesiology \& \\ Clinical Research}

The implication is based on descriptive data, $0.125 \%$ bupivacaine is better at lowering cortisol levels than oxycodone. However, there was no significant difference $(\mathrm{p}=0.515)$ between $\mathrm{T} 0, \mathrm{~T} 1$ and $\mathrm{T}$ on plasma cortisol levels after being tested with unpaired $\mathrm{T}$.

Bupivacaine is a long-acting local anesthetic. Like other local anesthetics, bupivacaine acts by blocking conduction or by inhibiting membrane depolarization by Na+. This drug prevents an increase in nerve permeability to sodium and potassium ions which causes the excitability threshold to increase, action potentials to decrease, nerve impulse conduction slows and nerve conduction finally does not occur. ${ }^{47}$ Epidural administration of bupivacaine has been shown to decrease cortisol levels after 30 measurements. minutes which is $147.45 \pm 22.36$ compared to general anesthesia which is $147.45 \pm 22.36 .{ }^{54}$

Research on the administration of local anesthetics in epidurals shows that local anesthetics are better in pain control because they can reduce morbidity and mortality, and can reduce the pathophysiological response to surgery. Administration of local anesthetics can reduce gastrointestinal motility, thereby reducing the risk of PONV. ${ }^{62-64}$ However, this study found that there was no significant difference between bupivacaine and oxycodone on cortisol levels. In other hand, bupivacaine and oxycodone are equally effective. This could be influenced by the effect of epidural anesthesia in lowering cortisol levels so that the difference in the effects of the two drugs was not clearly visible. According to the study itself, the effects of epidural bupivacaine can last up to 6 hours postoperatively and epidural oxycodone can last up to 10 hours postoperatively. Longer serial monitoring of cortisol levels of 0 hours, 6 hours and 12 hours may be needed to ensure the effect of these two drugs without being influenced by epidural anesthesia confounders. ${ }^{15}$

Oxycodone has a lower first-pass metabolism and has a higher bioavailability than morphine. Oxycodone demethylates O via CYP3A4 and CYP2D6 to become oxymorphone, the active metabolite that is three times more potent than morphine. Oxycodone is also metabolized by CYP3A4 to noroxycodone, which has weaker opioid receptor activity than oxycodone or oxymorphone. There are studies that suggest that CYP2D6 polymorphisms can make individuals require higher doses of oxycodone due to the production of less oxymorphone. This study did not examine gene polymorphisms, although there are potential confounders. This is because the incidence of this gene polymorphism is not high and there is still little evidence to support this statement. ${ }^{65}$

\section{Differences in side effects between test groups}

Table 5 shows no significant difference in side effects of chills, nausea and vomiting between the 


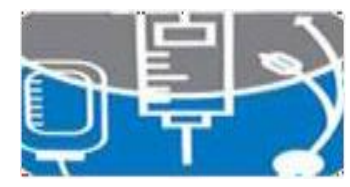

\section{Journal of Anesthesiology \& \\ Clinical Research}

administration of $0.125 \%$ bupivacaine and $5 \mathrm{mg}$ oxycodone. The majority of side effects in the oxycodone group were chills while the bupivacaine group was nausea and vomiting. The side effects of perepidural oxycodone have been tested in several studies. In patients undergoing total hip arthroplasty, it was found that oxycodone can cause mild pruritus but does not cause serious side effects such as respiratory depression, cognitive impairment or neurological disorders. These results are consistent with this study, that there were no serious side effects that had been mentioned. Similar to these findings, another study investigated side effects such as pruritus, nausea, vomiting, and respiratory depression in the administration of oxycodone and other opioids, namely morphine. Patients given epidural oxycodone had fewer side effects than patients given morphine. This is because the affinity of soxicodone for mu-opioid receptors is lower, which is about one tenth of that of morphine so that the side effects are lower despite having lower analgesia at the same dose as epidural morphine. ${ }^{15,50}$ it different to the results of this study, Piraiinen et al found nausea and vomiting as the majority side effect found in patients receiving epidural oxycodone whereas in this study more patients experienced side effects of chills. ${ }^{66}$ The high side effect of shivering in this study was influenced by various factors, including comorbidities, room temperature, and duration of surgery, and the patient's pain score. Epidural administration of drugs disrupts the body's thermoregulatory system by inhibiting vasoconstriction which plays an important role in body temperature regulation. In addition, epidural administration can also cause redistribution of body heat from below the trunk (below the level of blockade) to peripheral tissues which makes it easier for patients to experience hypothermia and shivering. influenced by several other factors such as age, duration of surgery, and the patient's pain score. Although the shivering mechanism is on the -opioid receptor, the affinity of oxycodone for this receptor is not as great as that of morphine, so the anti-shivering effect is not as great as that of other opioids.

According to the theory, the use of opioid drugs slightly increases the sweat threshold and slightly decreases the shivering threshold and vasoconstriction so that opioids can act as anti-chills although not all opioids have this anti-shivering effect. Taking morphine as an example, studies have reached different conclusions. There are studies which state that giving morphine 2-4 mg can not prevent shivering and there are those who state that giving pethidine, fentanyl and morphine are equally good for preventing shivering. Another study showed that pethidine was superior to morphine with equivalent doses in reducing shivering due to a longer onset of action than morphine.. ${ }^{70}$

Shivering itself has been shown to be influenced by individual subjective feelings and was not investigated further in this study. In addition, this study also did not measure when the shivering in patients stopped which is a limitation of this study. ${ }^{70}$ 


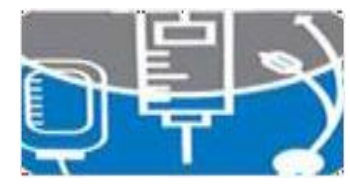

\section{Journal of Anesthesiology \& \\ ClinicalResearch}

Megahed et al found that side effects of nausea and vomiting were found in the majority of patients receiving $0.125 \%$ bupivacaine. Side effects such as chills have also been reported. This is consistent with the results of this study, nausea and vomiting as the dominant side effects of patients receiving bupivacaine. ${ }^{67}$ Another study examining the differences in side effects of bupivacaine and levobupivacaine found that the bupivacaine group had higher side effects, hypotension in 5 patients and nausea and vomiting in 3 patients. In this study, there were no side effects of hypotension and only nausea and vomiting. ${ }^{68}$

\section{Differences in BSS levels between test groups}

Table 6 showed the BSS levels before Bupivacaine $0.125 \%$ are $118 \pm 16$, while the BSS levels after are $128 \pm 27$. Meanwhile, for giving oxycodone $5 \mathrm{mg}$ perepidural, the BSS level before was $131 \pm 32$, and the BSS level after was $150 \pm 80$. In this study, after the Mann-Whitney test, it was found that there was no significant difference in the administration of oxycodone $5 \mathrm{mg}$ and bupivacaine $0.125 \%$ on BSS levels both preoperatively and postoperatively. Hypercortisolemia in the postoperative period has been shown to increase blood sugar levels through its negative impact on blood sugar clearance. Increased blood sugar levels can disrupt the mechanism of wound healing, namely causing disruption of keratinocytes, fibroblasts, macrophage function, impaired angiogenic response and production of growth factors that are important in wound healing. Therefore, it is important to control the postoperative stress response both in terms of drug

choice and anesthetic technique. ${ }^{29,30}$ Administration of bupivacaine in this study was better at preventing an increase in cortisol levels than oxycodone although there was no statistically significant difference. Research on the effects of bupivacaine on blood sugar levels alone has not reached a clear conclusion. There was a study that found bupivacaine was able to suppress blood sugar levels while other studies that compared the administration of bupivacaine under spinal anesthesia with general anesthesia did not find a significant difference between the drug in lowering blood sugar levels. However, spinal anesthetic technique may play a role in preventing the increase in blood sugar levels during surgery but postoperatively this effect can be masked due to the emergence of side effects such as nausea and vomiting that can increase blood sugar levels. ${ }^{69}$

\section{Conclusion}

There was no difference in the effect of giving bupivacaine $0.125 \%$ and oxycodone $5 \mathrm{mg}$ as postoperative epidural analgesia on cortisol levels preoperatively $(\mathrm{p}=0.650)$ and postoperatively $(\mathrm{p}=0.810)$. There was no difference in the effect of giving $0.125 \%$ bupivacaine and $5 \mathrm{mg}$ oxycodone as postoperative 


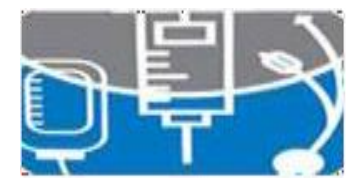

\section{Journal of Anesthestology \& \\ ClinicalResearch}

epidural analgesia to changes in cortisol levels $(\mathrm{p}=0.515)$.

Plasma cortisol levels on continuous administration of $0.125 \%$ bupivacaine as postoperative epidural analgesia of the lower extremities were $12.94 \pm 6.99$ after surgery and $11.32 \pm 5.42$ at six hours postoperatively. Plasma cortisol levels on continuous $5 \mathrm{mg}$ oxycodone as an epidural analgesia after lower extremity orthopedic surgery were $11.81 \pm 8.47$ after surgery and $11.82 \pm 7.56$ at six hours postoperatively. Side effects on continuous administration of $0.125 \%$ bupivacaine as epidural analgesia after lower extremity orthopedic surgery include chills (5\%), nausea (10\%), and vomiting (10\%). Side effects that occur on continuous administration of $5 \mathrm{mg}$ oxycodone as an epidural analgesia after lower extremity orthopedic surgery include chills (15\%), nausea (10\%) and vomiting (5\%).

\section{References}

1. Misiołek H, Cettler M, Woroń J, Wordliczek J, Dobrogowsk J, Mayzner-Zawadzka E T. The 2014 guidelines for Managemen, post-operative pain. Anaesthesiol Intensive Ther. 2014; 46(4): 221-44.

2. Özmen Ö, Özçelik F, Kaygın MA, Yılmaz H, Karakaya MA. Evaluation of pain scoring and free cortisol levels of postoperative analgesic methods in cardiac surgery: A new perspective. 2019; 27(3): 294-303.

3. Mwaka G, Thikra S, Mung'ayi V. The prevalence of postoperative pain in the first 48 hours following day surgery at a tertiary hospital in Nairobi. Afr Health Sci. 2013; 13(3): 768-76.

4. Anugerah S, Zainal R, Lestari MI. Gambaran manajemen nyeri pascaoperasi bedah ortopedi dan onkologi dengan anestesi umum di RSMH Palembang. Tesis. 2014.

5. Kang S, Brennan TJ. Mechanisms of postoperative pain. Anesth Pain Med. 2016;11(3):236-48.

6. Prete A, Karavitaki N, Bancos I, Yan Q, Prokop LJ, Alahdab F, et al. The cortisol stress response induced by surgery: a systematic review and meta- analysis. Clinical endocrinology.2018; 55905: 55467.

7. Mu D, Li L, Wang D, Li N, Shan G, Li J, et al. High postoperative serum cortisol level is associated with increased risk of cognitive dysfunction early after coronary artery bypass graft surgery: aprospective cohort study. Plos one. 2013; 8(10): 1-10.

8. Iwasaki M, Edmondson M, Sakamoto A, Ma D. Anesthesia, surgical stress, and "long-term" outcomes. Acta Anaesthesiol Taiwanica. 2015; 53(3): 1-6 


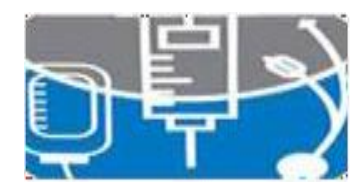

\section{Journal of Anesthesfology \&
Clinical Research}

9. Hall JE. Guyton and Hall Textbook of Medical Physiology. 13th ed. Philadelphia: Elsevier. 2016; 577600.

10. Nicolas W. Cortes-Penfield, Barbara W. Trautner RJ. The postoperative cortisol stress response following transsphenoidal pituitary surgery: a potential screening method for assessing preserved pituitary function. Physiol Behav. 2017; 176(5): 139-48.

11. Marc Mayberg SR, Patel A, Moloney K, Mercad J, Carlson A, Scanlan J, et al. Dynamics of postoperative serum cortisol after transsphenoidal surgery for Cushing's disease: implications for immediate reoperation and remission. J Neurosurg. 2017; 129(5): 1268-77.

12. Milosavljevic SB, Pavlovic AP, Trpkovic S V., Ilić AN, Sekulic AD. Influence of spinal and general anesthesia on the metabolic, hormonal, and hemodynamic response in elective surgical patients. Med Sci Monit. 2014; 20: 1833-40

13. Pathan H, Williams J. Basic opioid pharmacology: an update. Br J Pain. 2012; 6(1): 11-6.

14. Piirainen P, Kokki H, Hautajärvi H, Ranta VP, Kokki M. The analgesic efficacy and pharmacokinetics of epidural oxycodone after gynaecological laparotomy: a randomized, double-blind, double-dummy comparison with intravenous administration. Br J Clin Pharmacol. 2018; 84(9): 2088-96.

15. Kowalski G, Leppert W, Bienert A. Analgesic efficacy and safety of epidural oxycodone in patients undergoing total hip arthroplasty : a pilot study. J Pain Res. 2017; 2303-9.

16. Williams ACDC, Craig KD. Updating the definition of pain. Pain. 2016; 157(11): 2420-3.

17. Woessner J. Overview of pain : Classification and concepts. Pain Manag. 2018;35-7.

18. Steeds CE. The anatomy and physiology of pain. Surgery. 2016; 34(2): 55-9.

19. G Goyal S, Arora S, Rayasa MRS. Clinical aspects of acute post operative pain management and its assessment. J Adv Pharm Technol Res. 2010; 1(2): 97-108

20. Yam MF, Loh YC, Tan CS, Adam SK, Manan NA, Basir R. General pathways of pain sensation and the major neurotransmitters involved in pain regulation. Int J Mol Sci. 2018; 19(8): 2164-8.

21. Ip H, Abrishami A, Peng P, Wong J, Chung F. Predictors of postoperative pain and analgesic consumption. Anesthesiol. 2009; 111(3): 657-77.

22. Tai YH, Wu HL, Lin SP, Tsou MY, Chang KY. Influential factors of postoperative pain trajectories in patients receiving intravenous patient-controlled analgesia: a single-centre cohort study in Taiwan. BMJ Open. 2019; 9(11): 1-7. 


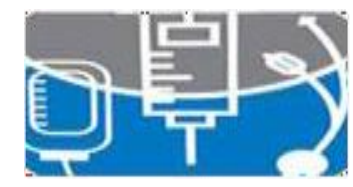

\section{Journal of Anesthesiology \&
Clinical Research}

23. Chia YY, Chow LH, Hung CC, Liu K, Ger LP, Wang PN. Gender and pain upon movement are associated with the requirements for postoperative patient-controlled iv analgesia: a prospective survey of 2,298 Chinese patients. Can J Anesth. 2002; 49(3): 249-55.

24. Bandeira RA, Gomes L de O, Bezerra AJC, Duarte JA. Correlation between preoperative anxiety and acute postoperative pain in elderly patients submitted to transvesical prostatectomy. Rev Dor. 2017; 18(4): 291-7.

25. Tracy LM. Psychosocial factors and their influence on the experience of pain. Pain Reports. 2017; 2(4): $2-4$.

26. Robleda G, Sillero-Sillero A, Puig T, Gich I, Baños JE. Influence of preoperative emotional state on postoperative pain following orthopedic and trauma surgery. Rev Lat Am Enfermagem. 2014; 22(5): 785-91.

27. Hawker G, Mian S, Kendzerska T, French M. Measures of adult pain. Arthritis Care Res. 2011; 63: 240-52.

28. Aggarwal K, Lamba AK, Faraz F, Tandon S, Makker K. Comparison of anxiety and pain perceived with conventional and computerized local anesthesia delivery systems for different stages of anesthesia delivery in maxillary and mandibular nerve blocks. J Dent Anesth Pain Med. 2018; 18(6): 367-73.

29. Miyajima K, Teoh SH, Yamashiro H, Shinohara M. Effects on glycemic control in impaired wound healing in spontaneously diabetic torii (SDT) fatty rats. Med Arch. 2018; 72(1): 4-8.

30. Hu SC, Phil MM, Lan CE. High-glucose environment disturbs the physiologic functions of keratinocytes: focusing on diabetic wound healing. J Dermatol Sci. 2016; 84(2): 121-7

31. Haroutounian S. Postoperative opioids, endocrine changes, and immunosuppression. Pain. 2018; 3(2): $1-5$.

32. Villafañe JH, Pedersini P, Bertozzi L, Drago L, Bishop MD, Berjano P. Exploring the relationship between chronic pain and cortisol levels in subjects with osteoarthritis: Results from a systematic review of the literature. Osteoarthr Cartil. 2020; 28(5): 572-80

33. Tennant F. The physiologic effects of pain on the endocrine system. Pain Ther.2013;2(2):75-86.

34. Nees F, Lö M, Usai K, Flor H. Psychoneuroendocrinology hypothalamic-pituitary-adrenal axis feedback sensitivity in different states of back pain. Psychoneuroendocrinol. 2019; 101: 60-6.

35. Zhang J, Zhang Y, Yan H, Zhang K. Influence of preemptive analgesia with oxycodone hydrochloride on stress hormone level of geriatric. J Coll Physicians Surg Pak. 2020; 30: 476-9. 


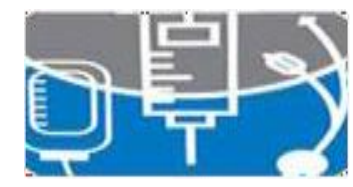

\section{Journal of Anesthesiology \&
Clinical Research}

36. Okur H, M K, Muhtaroğlu S, Kazez A. Effects of bupivacaine infiltration on beta-endorphin and cortisol release and postoperative pain following inguinal herniorrhaphy in children. Pediatr Surg Int. 1995; 11: $41-4$.

37. Butterworth JF, Mackey DC, Wasnick JD. Regional anesthesia and pain management. In: Morgan \& Mikhail clinical anesthesiology. 6th ed. New York: Lange Medical Books; 2018; 968-9.

38. Adrian H, Paramvir S. Epidural anesthesia. In: StatPearls. Treasure Island (FL): StatPearls Publishing. 2019: $1-5$

39. Berde CB, Strichartz GR. Local anesthetics. In: Elsevier, editor. Miller Anesthesia. 7th ed. Philadelphia; 2010; 922-3.

40. Hadzic A. Epidural blockade. In: Epidural anesthesia and analgesia.NYSORA. 2014; 10-9

41. Fukuda K. Opioid. In: Miller anesthesia. 7th ed. Philadelphia: Elsevier. 2010; 784-9.

42. Fischer B. Techniques of epidural block. Anaesth Intensive Care Med. 2012;13(11):539-44.

43. Twomey C, Tsui BCH. Complications of epidural blockade. 2007; 167-92.

44. Auroy, Y., Narchi, P., Messiah, A., Litt, L., Rouvier, B., \& Samii K. Serious complications related to regional anesthesia. Anesthesiol. 1997; 83(3): 479-86.

45. Kang XH, Bao FP, Xiong XX, Li M, Jin TT, Shao J, et al. Major complications of epidural anesthesia: A prospective study of 5083 cases at a single hospital. Acta Anaesthesiol Scand. 2014; 58(7): 858-66.

46. Bruton LL, Parker KL. Drugs acting on central nervous system. In: Manual of pharmacology and therapeutics. McGraw Hill. 2008; 366-70

47. Katzung BG. Local anesthetics. Drugs acting on central nervous system. In: Basic and clinical pharmacology. 9th ed. McGraw Hill. 2018; 246-8

48. Shafiei FT, McAllister RK LJ. Bupivacaine. In:Stats Pearl. Treasure Island (FL):StatPearls Publishing. 2020; 1-5

49. Ordóñez Gallego A, González Barón M, Espinosa Arranz E. Oxycodone: a pharmacological and clinical review. Clin Transl Oncol. 2007; 9(5): 298-307.

50. Yanagidate F, Dohi S. Epidural oxycodone or morphine following gynaecological surgery. Br J Anaesth. 2004; 93(3): 362-7.

51. Guy LW. Basic science review of anesthesiology. New York: Mc Graw Hill. 1997; 372-92.

52. Orak M, Karakoc Y UM. An investigation of the effects of the mean platelet volume, platelet distribution width, platelet / lymphocyte ratio, and platelet counts on mortality in patients with sepsis who applied to the Emergency Department. Niger J clin Pract. 2018; 21(5): 667-71. 

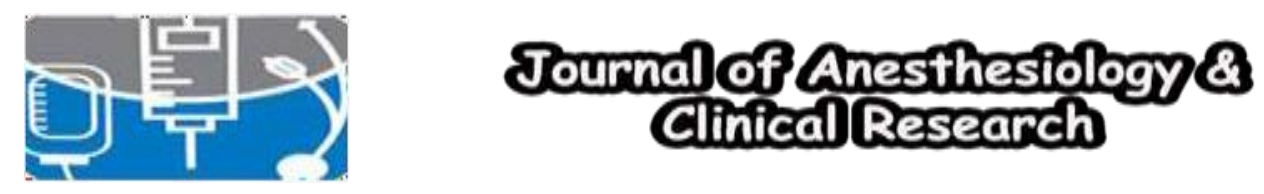

53. Barbieri A, Giuliani E, Genazzani A, Baraldi E, Ferrari A, D'Amico R, et al. Analgesia and endocrine surgical stress: effect of two analgesia protocols on cortisol and prolactin levels during abdominal aortic aneurysm endovascular repair. Neuro Endocrinol Lett. 2011; 32(4): 526-9.

54. Aggo AT, Ogan SF, Mato CN. The differential impact of two anesthetic techniques on cortisol levels in Nigerian surgical patients. Niger J Clin Pract. 2012;15(1):1-8

55. Ayca S, Gurkan T, Bekar A, Bilgin H, Korfali G. A comparison of spinal anesthesia characteristics following intrathecal bupivacaine or levobupivacaine in lumbar disc surgery. Eur Spine J. 2014; 23(3): $695-700$.

56. Lierz P, Gustorff B, Markow G, Felleiter P. Comparison between bupivacaine $0.125 \%$ and ropivacaine $0.2 \%$ for epidural administration to outpatients with chronic low back pain. Eur J Anaeshtesiology. 2004; $21: 32-7$.

57. Yovalina R, Zulkifli, Zainal R, Bahar E. Comparison of post operative epidural analgesia effect using continuous $0.125 \%$ bupivacaine with bolus $3 \mathrm{mg}$ morphine on insulin levels in patient. Maj Kedokt Sriwij. 2020; 52(3).

58. Sng BL, Kwok SC, Mathur D, Ithnin F, Clare Newton-Dunn PNA, Sultana R, et al. Comparison of epidural oxycodone and epidural morphine for post-caesarean section analgesia: A randomised controlled trial. Indian J Anaesth. 2016; 60(3): 187-93.

59. Bialka S, Copik M, Daszkiewicz A, Rivas E, Ruetzler K, Szarpak L. Comparison of different methods of postoperative analgesia after thoracotomy — a randomized controlled trial. 2018; 10(8): 4874-82.

60. Hadlow N, Collier S, Wardrop R, Henley D. Variation of serum cortisol with age and gender. 2011. Available from: https://www.aacb.asn.au/documents/item/508\#: :text=The nadir median cortisol was, at ages 35-40 years.\&text=Examining the span of ages, day in a large population.

61. 61. Khoo B, Boshier PR, Freethy A, Tharakan G, Saeed S, Hill N et al. Redefining the stress cortisol response to surgery. Clin Endocrinol. 2017; 87(5): 451-8.

62. Iwasaki M, Edmondson M, Sakamoto A MD. Anesthesia, surgical stress, and "long-term" outcomes. Acta Anaesthesiol Taiwanica. 2015; 53:99-104.

63. Zhang J, Tu Q, Gan J, Miao S, Zhou Y, Li Q et al. Preemptive Anti-Stress Response Effects of Oxycodone Versus Sufentanil for Patients Undergoing Cardiac Valve Replacement-A Randomized Controlled Trial. Clin Pharmacol Drug Dev. 2020; 9(3): 321-9

64. Winacoo, Jeffrey N, Maykel, Justin A. Operative Anesthesia and Pain Control. Clinics In Colon And Rectal Surgery 22:1. 2009; 41-46 


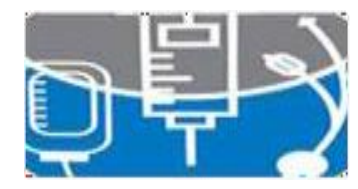

\section{Journal of Anesthesiology \& \\ ClinicalResearch}

65. Panu P, Kokki H, Heidi Hautajarvi, Ranta V, Kokki M. The analgesic ef fi cacy and pharmacokinetics of epidural oxycodone after gynaecological laparotomy: a randomized, double-blind, double-dummy comparison with intravenous administration. Br J Clin Pharmacol. 2018; 84: 2088-96.

66. Megahed NAE, Ellakany M, Elatter AMI, Teima MAAM. Anesthesia: Essays and Researches Comparison between analgesic effect of bupivacaine thoracic epidural and ketamine infusion plus wound infiltration with local anesthetics in open cholecystectomy. Anesth Essays Res.2014; 8(2): 1627

67. Kalsotra S, Chowadhary J, Dogra S, Gulati S. Comparison of the Effects of Epidural 0. $5 \%$ Bupivacaine and 0.5\% Levobupivacaine Administration Without Adjuvant Medication on Anaesthasia Quality, Side Effect Incidence and Analgesia Requirement Times in in Electively Operated Cases on Hip and Lower Extremity.JK Science. 2017; 19(1): 53-8.

68. Kouzegaran S, Sarjughi H, Tanha AS. Comparing the effects of general anesthesia and spinal anesthesia on the serum level of blood sugar in patients undergoing cesarean. Interv Med Appl Sci. 2018; 10(4): 202-206.

69. Mohammad A, Badiozaman R, Tahereh P. The efficacy of single dose of pethidine, fentanyl and morphine in treating postanesthesia shivering. Pak J Pharm Sci. 2011; 24(4): 516-7

70. Mohammad Y, Syed AH, Mudassir A, Salman W. Comparison between prophylactic low dose ketamine and ondasentronefor prevention of shivering during spinal anesthesia in patients undergoing lower abdominal surgeries. Professional Med J. 2015; 22(8): 1029-33. 